\title{
Research Title: Major Causes of Girls'School Dropout from General Primary Schools and Related Challenges in South Wollo and Oromia Zones in Amahara Region, Ethiopia
}

\begin{abstract}
Ali Yassin
Assistant Professor, Institution Of Behavioral Science and Teacher Education, Wollo University, Dessie,Ethiopia

Abstract

Though many researchers have been concerned with school dropout issue for both girls and boys, dropout pattern significantly differs by the gender of the students. This study clarifies the factors that contribute to the increasing dropout rate of children, particularly among girls by interviewing research participants and making a detailed review of available literature. Most past researches and reviews on the school dropout issue have been carried out regardless of the gender of the students. Twenty-five primary school students (10 boys and 15 girls), ten school teachers (including school directors) and twenty parents were interviewed for the study. That made the total research participants fifty-five. Dropout rate does not occur through a single factor; it is a composition of several factors. A number of studies have been conducted on girls' dropout issue based on particular regions, societies and cultural perspectives in various parts of the world. In this study, Ianalyzed the factors contributing to the dropout of girls and concluded thatthe major factors are (1) economic factors: e.g. poverty and migration to foreign countries to earn (2) household level factors: e.g. child labor (3) school level factors: e.g. distance and (4) cultural factors: e.g. early marriage.
\end{abstract}

Keywords: School dropout, girls' education, educational inequality.

DOI: $10.7176 / \mathrm{JEP} / 11-10-03$

Publication date: April $30^{\text {th }} 2020$

\section{INTRODUCTION}

\section{BACKGROUND OF THE STUDY}

In Ethiopia, while the net enrolment rate for first cycle primary has reached to 86.6 per cent in 2009/10 surpassing the ESDP III target of 82.6 per cent for the same year, high dropout rates in the initial years of schooling and low completion rates in the second cycle prevented the achievement of the targets for primary education as a whole. The dropout rate is very high in grade one and is slightly higher for girls than boys. The contributing factors for drop out are multiple. Many families do not appreciate the benefits of schooling and children have few opportunities for secondary education. These factors are all closely linked to poverty.

Strides have been taken to increase the participation of girls, but continued efforts are needed to reach the MDG target through eliminating gender disparity as it appears that more boys than girls are being enrolled. Continued support should be given to enhance girls' participation and achievement in education in addition to co-curricular activities to be undertaken by school clubs and other organizations aimed at preventing drop-out. Although it declined in 2008/2009, the repetition rate has nearly doubled. Between 2003/04 and 2007/08 and it is higher for boys than for girls. In order to address this challenge, it now becomes normal to arrange tutorial classes especially for girls though the result is not yet at the required level. Attributed to various socio-economic and cultural factors, girls are more susceptible than boys in both respects: repetition and drop out. It is therefore important to investigate the agenda in order to implement strategies that reduce both in-school and out of school factors.

\section{Statements of the Problem}

Known to be a foundation to the nation's accelerated socio-economic development, governments have made tremendous strides in promoting girls' education ever since 1970s. However, in Ethiopia and other African countries, getting girls into school and retaining them in schools is a very serious constraint as result of which girls' enrollment and achievement in education does not yet reach at the required level in the Sub-Saharan African countries. Studies undertaken at various times pertaining to girls' education ensure that the deep rooted misinterpretation and biased attitudes in the community, economic and education inequality related issues, and far less attention are the main causes to the problems of the education ofgirls (National Girls' Education Strategy, NGES 2010).

As regards, to minimize and get rid of biased attitudes on girls and factors that influence the participation of girls in education, and address the equity aspect of education services to citizens, the first, second and third education sector development programs have been realized within the framework of the Education and Training Policy. In these programs gender issue was a strategic direction with a special focus given to balancing the rates of enrollment and achievement of girls and boys at all levels of the education system. Besides, in improving the 
participation of women in the management of schools and teaching profession, remarkable changes have been recorded in the sector. In order to boost these changes and ensure integrated gender equality in the education sector, further research is found to be crucial. Evidences have to be collected not only from statistical perspectives per se but also from narratives of the lives of the girls by themselves (NGES 2010).

Upto 2008/09 primary Gross Enrollment Ratio (GER) in primary school nationally stands at $94.2 \%$ where the rate for boys is $97.6 \%$ and the rate for girls is $90.7 \%$. In the same period the average Net Enrollment Rate (NER) was $83.0 \%$ out of which the rate for boys is $84.8 \%$ and the rate for girls is $81.3 \%$. The variation in gender gap in primary school narrowed from $16.5 \%$ in $2004 / 2005$ to $6.9 \%$ in $2008 / 2009$. In the same period the NER narrowed from $9.6 \%$ to $3.3 \%$. In the previous years, the survival rate of boys in primary school was better than girls. Nowadays, it can be observed that the survival rate of girls at primary level has shown a substantial increase (ibid).

In Ethiopia, the overall obstacles to advancing female enrolment and achievement in education are indicated as follows. The first obstacle is the long-standing cultural misconception of the community and the family more specifically: early and forced marriage, verbal insult, beating up, insecurity, rape, etc. persist unresolved until now. The second obstacle is economic problem related to insufficient involvement of concerned government bodies, community and parents in mobilizing resources to finance, and little focus in creating sufficient opportunities to girls' education, the demand by parents on girls' labor, specially, as those parents having low income do not afford to cover costs for stationery and food, they are reluctant to send their children to school.

Experiences of the researcher show that the dropout rate of female students in schools is so high as compared with their male counterparts (Abebayehu, 1998). Here, it seems clear that though the Ministry of Education has tried to increase the enrollment of girls at every educational institution, many female students dropped out from learning institutions in each year and in every semester. Thus, the problem of female students' dropout at primary schools seems worth investigating. To the best knowledge of the researcher, much has not been done to investigate the probable causes to the problem at hand in detail in the region.

As the policy documents reiterated and the experience in the Amahara Regional state in particular and in Ethiopia in general revealed, girls' enrollment rate has tremendously increased from primary to tertiary levels. However, daily experience and informal discussions with primary school teachers depict that at least 20 to 30 female students get married before completing grade eight in certain schools in certain woredas. For example, in Bekie General Primary school which is found in in QalluWoreda, South Wollo Administrative Zone in Amahara Region at a distance of nearly 20 Kilometers South East of Kombolcha Town, 25 female students were married before completing grade eight in 2014 within a semester (Ali, 2015).

The problem is associated not only with early marriage which is disservice for girls' education on its part but also the very objective why they are getting married: They get married to just for temporal purpose since their aim is "to be transformed into a womanhood locally called "mekenetwuanfetach" by that marriage and then be ready for exile to the Middle East on foot or by air. This is the rumor. Is it fact or fiction? If so what are the stakeholders in the region doing? Or more correctly what should they do? Studies, as discussed earlier, mentioned so many factors for the low participation and low achievement level of girls from cultural to economic to distance of schools despite the fact that some of such problems are being alleviated by the social and governmental efforts in Ethiopia. Research reports identified the economic problem of households including migration of parents. But little is said about the migration of teenage girls by boycotting their basic primary education. I assume this problem to be prevalent especially along the route from Kobo via Woldiya town to Kombolcha, Kemissie town and ShewaRobit, all of which are located in Amhara Regional State. Many researches are also infected with statistical data with or no emphasis on the narratives of the girls lives in their own voice. It was in the light of this problem that the researcher was initiated to undertake this study in Second Cycle Primary Schools.

\section{Objectives of the study}

The study is mainly intended to:

a) Investigate the major factors that cause for girls' dropout from Second Cycle General Primary Schools in South Wollo and Oromo Zones.

b) Differentiate the major related challenges to girls' education in selected schools

\section{RESEARCH QUESTIONS}

To achieve the above stated objectives, the following research questions were raised:

1. What are the factors that cause girls' dropout from schools before completing Grade Eight?

2. How can stakeholders reduce and if possible avoid girls' dropout in general and early marriage and teenage migration in particular? 


\section{Significance of the Study}

This study could be valuable in that:

a) It may give a chance for teachers and other stakeholders to know more about the contemporary challenges of girls' education and thereby act accordingly.

b) It will inform educational administrative bodies at different levels about the causes of dropout at selected woredas and schools so that they can intervene to solve the problems, if any.

c) It can be used as a reference for further research on girls' education for the future.

\section{Delimitation of the study}

The focus of this study was to assess the causes of female students' dropout and related challenges at selected woredas and General Primary Schools in South Wollo and Oromo Zones. For this purpose the participants of the study will be students, teachers, parents, principals, parent-teacher association members, supervisors. Out of the available woredas from the two Zones, six Woredas (QaluKombolcha, QalluQutir 2, Argobaworeda, DawaChefa,ArtumaJille, and Bati) were included comprising urban and rural primary schools from the three ethnic groups in the region: Amhara, Oromo and Argoba.

Twenty-five primary school students (10 boys and 15 girls), ten school teachers (including school directors) and twenty parents were interviewed for the study. That made the total research participants fifty-five.

\section{Definition of Terms}

a) Dropout: refers to giving up attending schools before the completion of the academic year and/or General Primary School due to different causes other than death.

b) Early marriage: refers to marriage before the age of eighteen as enshrined in Ethiopian policy documents.

c) Migration: refers to leaving for abroad mainly to the Middle East for looking after jobs.

\section{Methods of Data Collection \\ Conducting Interviews}

Twenty-five primary school students (10 boys and 15 girls), ten school teachers (including school directors) and twenty parents were interviewed for the study. That made the total research participants fifty-five.

\section{Data Presentation, Analysis, and Interpretation}

According to the World Conference on Education (2001), all children, particularly girls, might have access to and complete quality education by the year 2015. That ended up unfulfilled. We know it very well that both boys and girls have equal right to be educated and in developing a nation it is important to provide education irrespective of gender.

A growing body of literature shows that girls' dropout rates are higher compared to boys' in most parts of the world. For instance, according to UNESCO (2012), the dropout rate is higher for girls in 49 countries compared to boys. Chimombo (1999) observes that though the enrolment in school is almost same for girls and boys, boys have a higher likelihood of continuing school compared to girls. Holmes (2003) also found that girls overall attain less education and tend to drop out earlier as compared to boys.

Thus, when dropout rate varies by gender and if girls tend to drop out earlier compared to boys, it manifests that there are some unique factors contributing to the increase in the dropout rate, particularly for girls. In other words, there are some factors which extensively contribute to an increase in girls' dropout though those factors also impact dropout rate for boys. In this respect, the findings ofHolcamp (2009) also support the argument when the author found that some socio-cultural factors highly impact girls' dropout rate though those factors also contribute to boys' dropout rate but to a lesser extent. Therefore, we can argue that some particular factors produce poor educational outcome which consequently increase the dropout rate for girls. Therefore, from this viewpoint, the main objective of this study is to clarify which factors contribute to the increase in the dropout rate, particularly among girls which are not quite clear in past research and reviews on the dropout issue. Dropout rate does not occur through a single factor; it is a composition of several factors. A number of studies have been conducted on girls' dropout issue based on particular regions, societies and cultural perspectives in various parts of the world. In this study, I analyzed and reviewed the factors and illustrate a conceptual framework of dropout for girls which can give further opportunity to researchers to view the relevant factors on girls' dropout issue. For better demonstration I have categorized all the factors into four groups which are (1) economic factors, (2) household level factors, (3) school level factors and (4) cultural factors. 


\section{Economic Factors}

Unequal Parental Investment for Boys and Girls

Parental investment for children's well-being can sometimes become gender biased. Although parents are altruistic to the gender of their children, they do not invest in education equally for all. In this regard, there are considerable evidences in the literature (Glick \&Sahn, 2000; Kingdon, 2005) supporting this view whereby that, there is gender bias or pro-male bias in case of parental investment in children. In addition, Leung and Zhang (2008) found that parents' preference for sons encourage more of them to invest for in their sons' well-being to take care of parents in the future. In fact, parental gender bias investment occurs particularly when parents have limited/lower income and resource, causing girls to leave school earlier than boys.

"Parents in the rural areas still expect that girls sooner or later will get married and hence no need for greater investment for their education" (a school director in Qalluworeda reported).It was also reported that girls are meant either for marriage or exile to Middle East. This has got a negative effect on the education of girls since it can rob the hearts and minds of the girls.

\section{Schooling Costs}

Direct and indirect schooling costs are important factors for the education of children and some research indicate that schooling costs especially school fees, are a central reason for early dropout from schools. Schooling costs are sometimes linked to the gender of the children as parents are sometimes become unwilling to pay schooling fees for their daughters. Several parents reported that especially whenever there is shortage of rain, families fail to cover school fees (such as for uniforms and even books) for girls as well as boys whenever they have got more than one child.

\section{Poverty and Migration}

Many girls dropped out of schools from different grade levels and left the country by air or by sea and on land. The former transportation system is acceptable but the latter is very deadly. One school dropout from grade seven reported:

Many girls dropped out of school. They interrupted their schooling from grade five, grade six, grade seven and grade eight. There is no exception in school dropout whether from grade ten or grade twelve. Even civil servants like teachers with college diplomas migrated to the Middle East.

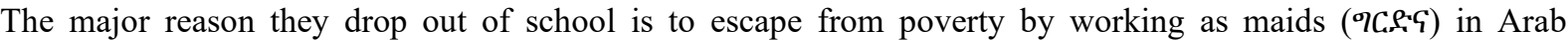
countries. Unfortunately, not all achieve their objectives. They may die on the journey, or may be raped especially those who travelled on lane and by sea through illegal brokers. Others may be mentally ill. Exile is horrible (Khedija, school dropout, December $11^{\text {th }}$ 2019).

\section{Death of Parents who was the source of income}

A mother reported:

When the father of my children died, our source of income was cut. He was a daily laborer. Since I am sick since the last ten years, I cannot work like him to support my family. The elder daughter dropped out of the school from grade seven and she is now selling certain vegetable items on the road side (gulit) to feed us (Mother Alemitu, December 17th 2019).

Orphan children are among the dropout students from schools in many cases.

\section{Household Level Factors \\ Household Work}

Informants reported that that if mothers work and get wage outside of the home, female children take some responsibilities of the household which causes them to drop out (Fuller \& Liang (1999). In general, girls take more loads of household chores than the boys and on the other hand rural girls do more household works than urban girls (cooking, fetching water, collecting firewood, baby-setting, even weeding crops and sheep and cattle herding (Ersado, 2005).

\section{SCHOOL LEVEL FACTORS}

Poor school facilities and infrastructures

Many Schools do not have appropriate water taps and toilet rooms. The available toilet-rooms are with poor sanitation. All this may repel girls from schools. In addition, Ngales (2005) found that in Ethiopia, female students were often absent in class during menstruation and frequent absence led them to drop out from school, however.

\section{Absenteeism}

Research also indicates that irregular attendance can be a precursor for dropping out from school regardless of 
the gender of the pupils. However, it can be argued that school absenteeism can be somewhat negatively more effective for early dropout from school for female students. In this regard, Manacorda (2012) also argues that girls are at a greater risk of absenteeism, repetition and dropout, and have lower educational achievement than boys in upper primary school. There are some causes for girls' dropout because of absenteeism. Girls also can more frequently drop out because of absenteeism due to child labor or household work. There is a good deal of literature on household work found that girls do more household work than boys which may increase nonattendance in schools for girls.

\section{Feminine Facilities in Schools}

Inadequate sanitation facilities in schools massively affect girls' dropout because this inadequacy indicates that schools are not safe for girls. Lizettee (2000) observes that though lack of facilities and poor hygiene affect both girls and boys, sanitation in schools has a strong negative impact on girls.

UNICEF (2009) further notice that separate hygienic toilets should be made available for boys and girls when designing the facilities of a school. UNICEF (2006) observe that in Africa, the lack of basic sanitation is the cause decreasing enrollment of girls in schools but girls spend more time in schools when sanitation facilities are adequate. UNICEF (1998) further observe that if the toilets are shared by girls and boys or are closely located in schools a significant number of girls drop out because of harassment and lack of privacy.

\section{Teachers' Attitude}

Many researches have examined how teachers' attitudes toward female students are linked to dropout issue. Colclough et al. (2000) found that in Ethiopia, teachers in school more positively viewed boys than girls because they usually expect girls to quit school early. Teachers' attitude and their teaching practices have foremost impact in sustaining girls in schools. According to Nekatibeb (2002) study from several countries in SubSaharan Africa indicate that both female and male teachers believed that boys were academically better than girls. This study also found that most teachers tend to pay more attention to boys in the classroom than girls. Research by Fawe (2001) shows that teachers were not conscious in using their language toward girls in the classroom. They also viewed girls as less intelligent to those boys and that girls are just there to marry early.

\section{School Distance}

School distance is an important determinant of school dropout for female students. Juneja (2001) observes that if school distance is considered too far from home, young girls tend to drop out more due to the vulnerability to sexual harassment, fatigue and lack of residential area near the school (Colclough et al., 2000; Nekatibeb, 2002). Parents are afraid for the safety of their children when they have to travel longer distances to school. Nekatibeb (2002) also reports that school distance is the foremost obstacle for girls' education in many countries in Africa. A large number of studies in African regions report that school distance can discourage girls from being educated for two major problems. One of them is the length of time and energy needed to cover the distance for children with poor diet or empty stomachs. Another is parental anxiety about sexual safeguard of their daughters. School distance gives the motivation to girls to stay out of school. Ainsworth et al. (2005) found that close proximity to schools had a positive motivating impact on girls.

In the South Wollo and Oromia Zones, elementary schools are established at closer distance for children. That cannot be the threat for girls' dropout as such. However, many girls drop out of school after the completion of Grade Eight since Secondary schools are far away from their residential areas. For example, "students from Argobaworeda must travel more than thirty-seven $\mathrm{km}$ away from their villages at an average. Consequently, many girls in this area do not have the chance for secondary school education" (Teacher Halimet, November $20^{\text {th }}$, 2019).Parents are also economically weak to hire a house in urban areas as the area is frequently draught stricken.

\section{Low School Performance}

Basically in the General Primary schools, students are not as such forced to repeat classes. The practice is helping students to pass grades without discrimination. Even so, certain girls predict the future and decide for themselves to dropout from school since continuing their education is meant wastage of time as their performance will not allow them to be employed in lucrative professions since the competition is tough. One of the dropouts stated as follows:

I may pass from grade to grade but unless I score best grades, I consider staying in school will only reduce my life span. Hence, I dropped out early in grade seven, went to Arab country, worked for eight years and now I am here with my own house and child (School dropout, Hanan, November 20th 2019).

The parents and close relatives also do not appreciate the education of girls if they are not smart enough academically. 


\section{Students' Poor Attitude to Education}

In one of the schools in the region, I read graffition the wall of the classroom in Amharic that reads

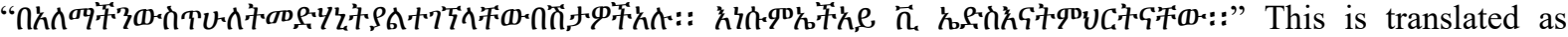
"there are two diseases in the world that are incurable: HIV/AIDS and Education". I was shocked to encounter such exaggerated negative attitude of students on the wall of classrooms.

Other research participants reported that there is no need for staying in schools since those who have graduated even from universities are jobless. Hence, they think that it is timely to dropout in early grades even without completing general primary education. I understand that this will have its own repercussion in the future life of the individual as well as the society.

\section{Cultural Factors}

\section{Early Engagement for Marriage Arrangement}

Whenever a girl is proposed for marriage in the future, there is a kind of festivity called engagement $\left(\hbar 6^{8} 34\right)$. During this period which may stay for from one upto five years, girls stay with their parents decorated with necklaces (called birbis and dinbil), golden ring as a sign of engagement, a hand watch (a recent inclusion in QalluWoreda), and feather (laba) (in ArgobaWoreda). Such cultural materials are always worn by the girl who has made an engagement and known by her peers and the people around. The girl may feel shy as she understands that sooner or later, she may get married and ends up with dropping out of the school.

Girls do not drop out of school because of engagement in South Wollo and Oromia Zones except girls from ArgobaWoreda. They are predominantly Muslims and they feel shy once the engagement ceremony is conducted. Hence, they drop out of schools just because they are going to be married after two or even three years (Teacher Halima, May $17^{\text {th }}$ 2016).

\section{Early Marriage}

Regarding the effect of early marriage on girls Holcamp (2009) found that in rural areas girls' dropout rate became higher because parents consider girls' schooling as of no benefit when they leave their own family after getting married. Mansory (2007) also found that early marriage is the foremost cause of early school dropout of girls in Afghanistan. A lot of research have highlighted on girls' age and education and found that when girls reach puberty, parents consider it is time for them to be married and tend to arrange the marriage instead of continuing schooling (Molteno et al., 2000). This is particularly true for Woredas like Qallu, Argoba and Oromia Zone. Some studies argue that early marriage of girls is associated with dropouts in certain contexts. For instance, in societies where girls leave parental household after marriage, girls' dropout might be higher in that society (Ackers et al., 2001). Shahidul (2012) also found that girls with lower socioeconomic backgrounds drop out from secondary school more frequently.

My analysis of data from Research participants revealed that there are three cases related to early marriage and schooling. In case one, female students drop out of school right beginning from the day of engagement for marriage (metachet) as described above. This is especially unique to ArgobaWoreda. In case two, female students drop out of school after the wedding arrangement but not during the day of future marriage arrangement unlike the Argoba girls. This is practiced in QalluWoreda. The third case represents the best practice wherein female students never dropout of schools whether they are engaged or married. This is common in Borena and SaintWoredas. Research participants reported the cases as follows:

Girls in Argoba areas never come to school whenever they put a necklace called birbis and a feather in their head as a sign of being having a fiancé. They are interested for marriage and not for further education (Teacher Halimet, July 20 th 2016). Girls in QalluWoredaput a necklace and a hand-watch as a sign of having a fiancé in the rural area but they do not drop out of school at this stage. Rather, they quit their academic life after the wedding ceremony. Most of them feel shy to come back to school (Teacher Ekram, July 25th 2016). In Borena and SayintWoredas, female students do not drop out due to marriage associated case. If they marry this week, they may come after two or three weeks without being shy for being a student and a house wife (Teacher Demeke, June $15^{\text {th }}$ 2016).

I understand that those people who live in these areas should share experiences to tackle the problem of girls' dropout. Of course, governmental bodies in the localities try to enforce to ban early marriage whenever possible. Especially teachers and school directors attempted to fight this bad practice of early marriage by taking the case to the court. However, they did not win the case in many scenarios. A teacher reports:

Whenever a girl is absent from the class and whenever rumor is heard for the marriage of a schoolgirl, teachers and directors sue the would be groom to cancel the marriage proposal or to postpone the wedding based on the law of the land that prohibits early marriagei.e. under eighteen referring to the age of the girl based her school records. Unfortunately, the family of the girl (and the boy) defend given the case to the court by having eye-witnesses for confirming the age of the girl to be eighteen and even more. In this manner, the teacher and the school director come back ashamed of their act. And the community has given them a bad name 


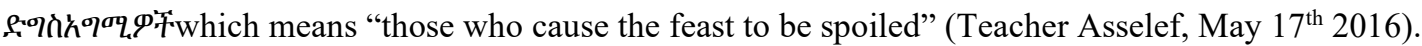

I understand that such a practice is adding an insult to injury to the status of the teaching profession.

\section{Temporal Marriage}

Not all early marriages are temporal marriage since such marriages may last for life. However, there is a recently introduced marriage practice that is not even religiously accepted: temporal marriage. In Muslim tradition, if a person plans the marriage to be temporal, this not marriage but prostitution.It is unfortunate to learn that in the Woredas like Qalu, young girls are married just for a month or six just to enable them transform into womanhood and thereby be ready for the harshest exile on land and by see which is mostly done by illegal brokers. A girl married is called "meqenetwanfetach"to connote her adulthood. A research participant described the case as follows: "Many girls get married this week and then they get divorced the following week just for exile to Arab countries". Sometimes the new couple may migrate together if they are lucky" (Teacher Ekram, August 20 $0^{\text {th }}$ 2016).

\section{Pregnancy}

Teenage pregnancy is a significant cause of school dropout for girls especially in urban areas (Boyle et al., 2002). Some studies argue that there are some specific characteristics of girls with dropout status which are: Girls with poor school performance, girls who have experienced temporary dropout previously, low economic status, family migratory life styles and the consequent vulnerability of girls. Dunne and Leach, (2005) argue that some unexpected circumstances of girls such as lack of social and economic opportunities and gender inequality in education system lead to motherhood and consequence dropout from schools. Dunne and Leach (2005) state that the dropout rate of girls is higher than the dropout rate of boys and the foremost cause for girls to drop out is pregnancy.But in the Ethiopian context there are dropout cases but it is not the major cause of dropout. Though some countries permit girls after getting pregnant to return to school, research found that the re-entry rate is not much higher. According to Grant and Hallman (2006), re-entry to school after pregnancy depends on some circumstances such as if they can get caregiver for their child and if they are able to share or relinquish childcare responsibilities.

\section{Peer- Pressure}

Many students drop out of schools due to peer influence. One of the participants from the dropouts described this case as follows:

I dropped out simply by looking at my school mates who dropped out of the school. It was just like a

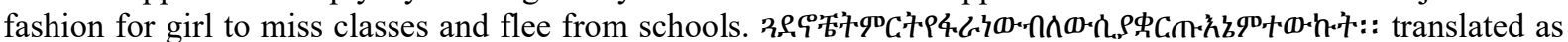
whenever my peers said to me learning is for the ignorant, I believed them and dropped out of school just like them and then I preferred migration (Khedija, November $11^{\text {th }} 2019$ ).

Those dropouts who did not complete even grade eight told me that they faced different challenges due to their poor educational level from inability to use social Medias to following road-direction in International Airports and keeping personal diary.

\section{Parental Pressure for Migration}

Research participants repeatedly reported the urge parents have for allowing and mainly compelling their daughters to go to the Middle East and thereby work and earn some amount of money so that they can "escape from poverty". Because of such influences young men are usually forced to live single or divorced due to the female exodus in the region. A parent went for asking a marriage proposal:The father of the daughter replied to the marriage proposal negatively saying, "My daughter is my ISUZI (she is my source of business). What kind of crimes have I done against you to propose for marriage for my only child as I was in a hurry to send her to the Middle East?" All the elderly people who accompanied for the presentation of the marriage proposal were shocked by the answer of the father and came back heads down. If the girl desist to go to exile, her parents and even close relatives repeatedly counsel the girl to go either by air or on land. A father was reported saying:

Have you seen the daughter of AtoYimer? She sent him 70, 000.00 Birr and now he has bought a Bajaj. He is also planning to construct a big house. Don't you like to help me improve my life? If you are not voluntary to help me by working abroad, you must help yourself since I am poor, I do not have any thing for inheritance for you. I am not lucky like AtoYimer (Parent Ato Ahmed, April 20 2019).

\section{Academic failure}

In the region,students in general primary schools do not face challenges in their academic efforts. "Grade repetition is also a rare practice since there is a tradition of giving tutorials and exams for those boys and girls who missed class-attendance even for several months" (Student Fatuma, September 1/2019). 


\section{Parental Attitude for Girls' Education}

Parental attitudes to girls education is still negative especially in woredas like rural Qallu, Argobas and Oromia zone since they believe that a girl is meant to be a house wife married early before being spoiled by the urban and modern life styles. That sort of negative attitude is reducing through the passage of time but still the communities attach greater value to the chastity of the girl as a sign of decency and politeness. One parent reported from Kombolcha town:

"In Qallu especially Kebeles like Beke, Ancharo and the like, a girl is meant for marriage and establishment of decent family. That is all. Sending daughters to modern schools is a recent practice. Many parents Still prefer marriage of thir daughter to the nearby young men to sending their children to schoolsn, (Ato Hussein, September10 $0^{\text {th }} 2019$ ).

\section{Conclusions}

All in all the major factors that enhanced the dropout of girls from General Primary Schools include:

I. Economic Factors,

- The tendency to invest less on girls' education and more for boys' education

- Inability of parents to cover school costs (expenses for uniforms, exercise books, books, bags etc)

- Poverty motivated migration

- Death of the parent who was the source of income

II. Household Level Factors

- Household work: fetching water, collecting firewood, baby-sitting, looking after cattle

III. School Level Factors

- Poor school facilities and infrastructures

- Lack of model female teacher from the villagers

- Absenteeism

- Teachers' negative attitude to girls' education

- Students and parents' poor attitude to girls' education

IV. CulturalFactors.

- Low school performance e.g. repetition of grades

- Early engagement for marriage

- Early marriage

- Temporary marriage

- Pregnancy

- Peer pressure

- Parental pressure for exile

\section{RECOMMENDATIONS}

Based on the above discussion, this study provides a few important recommendations which the policy planners may adopt for future intervention. Governments should plan some special polices to improve female education like introducing special stipends for female students and also making education free for them including school uniforms. The government has started helping drought stricken areas and in some schools there is schoolfeeding program and safety-net practice in the region. Although already the government has taken some steps in this regard, it is important to expand it further in collaboration with non-government organizations and the community as a whole. It is also necessary for the government to invest more money in making the environment favorable and sensitive for girls' education. Governments should also provide school supplies adequately according to the demands of the students.

\section{REFERENCES}

Abena, F. D.(1991). The Emancipation of Women An African Perspective. Accra: Ghana Universities Press. ww.jstor.org/stable/525186

Ainsworth, M. (2005).Socioeconomic Determinants of Fertility in Sub-Saharan Africa: A Summary of the Findings of a World Bank Research Project. Washington D.C.: The World Bank

Atayi, J. B. (2008). Disabling Barriers to Girls' Primary Education in Aura District (Uganda) - An Intersectional Analysis. A Research Paper presented in partial fulfillment of the requirements for obtaining the degree of Masters of Arts in Development studies.

Carrell, Scott E., Marianne E., Page \& James, E. (2010). Sex and Science: How Professor Gender Perpetuates the Gender Gap? Quarterly Journal of Economics, 125 (3),1101-1144

Chege, F.,\&Sifuna, D.N. (2006). Girls' and Women's education in Kenya gender perspectives and trends, www.library.unescoiicba.org/ 
Ersado, L. (2005). Child labor and schooling decisions in urban and rural areas: comparative evidence from Nepal, Peru, and Zimbabwe. World Development, 33(3),455-480.

Fuller, B. \& Liang, X. (1999).Which girls stay in school? The influence of family economy, social demands, and ethnicity in South Africa. Washington, DC: National Academy Press.

Glick, P. \&Sahn, D.E. (2000). Schooling of girls and boys in a West African country: the effects of parental education, income, and household structure. Economics of Education Review, 19, 63-87.

Grant, M., Cynthia B. Lloyd, and Barbara Mensch. (2013). Menstruation and school absenteeism: Evidence from rural Malawi, Comparative Education Review 57(2): 260-284.

Holcamp, G. (2009). Researching the girls' dropout rate in Malawi. Why girls dropout of primary schools and in what way this rate can be reduced. Master Thesis Special Education.

Juneja, N. (2001). Primary Education for All in the City of Mumbai, India: The Challenge Set by Local Actors. School Mapping and Local-Level Planning. Paris: UNESCO.

Kapakasa, A.M. (1992). Determinants of girls' participation and persistence inschool.Washington, DC: World Bank Population and Human Resource Division, South Africa

Khan, R.E.A. and Ali (2005).Bargaining Over Sons and Daughters' Schooling: Probity analysis of household behavior in Pakistan. Working Paper 01-05, Department of Economics, Islamic University, Bahawalpur, Pakistan.

Leung, M. C. M., \& Zhang, J. (2008).Gender preference, biased sex ratio, and parental investments in children in single-child households.Review of Economics of the Household 6(2) 91-110.

Lloyd, C.B., Mete, C. \&Sathar, Z.A. (2005) Effect of Gender Differences in Primary School Access, Type, and Quality on the Decision to Enrol in Rural Pakistan. Population Council, World Bank. www.popcouncil.org/uploads/pdfs/wp/164.pdf

Mansory, A. (2007), Drop out Study in Basic Education Level of Schools in Afghanistan, Kabul: Swedish committee for Afghanistan. www.nzdl.org/gsdlmod

Ngales, M. (2005).School girls: towards health, dignity and wellbeing. Retrieved October 7th from. www.wateraidethiopia.org.

Nixon, L. A., \& Robinson, M. D. (1999). The educational attainment of young women: Role model effects of female high school faculty. Demography, (36)2, 185-194.

Njau, W., \&Wamahiu.S. (1994).Ministrial Consultation on School Dropout and Adolescent Prignancy. Nairobi: Working Papers Series no. 7.

Pong, S., Dronkers, J. \& Hampden-Thompson, G. (2003). Family policies and children's school achievement in single versus two-parent families. Journal of Marriage and Family, 65(3), 681-699.

Sarmistha, P. (2004). How much of the Gender Difference in Child School Enrolment Can be Explained? Evidence from Rural India.Bulletin of Economic Research, 56 (2),133-158.

Save the children, state of the world's mothers. (2005).The power and promise of girls education. http://www.google.co.ke/search.

Shovan, G. \&Susmita, S. (2012). Direct and opportunity costs of schooling a girl child: A case study of puncha block of purulia District, West bengal, India. International Journal of Current Research, (4)12, 376-381.

UNICEF (2006). We can do a much better job! The Malawian process to community based school sanitation. UNICEF, New York, available at http://www.washinschools.info/page/323. European Journal of Research and Reflection in Educational Sciences Vol. 3 No. 2, 2015 ISSN 2056-5852 